\title{
Does 1:1 Computing in a Junior High-School Change the Pedagogical Perspectives of Teachers and their Educational Discourse?
}

\author{
Yehuda Peled \\ The Western Galilee College, \\ Acre, Israel
}

YehudaP@wgalil.ac.il

\author{
Ina Blau and Ronen Grinberg \\ The Open University of Israel, \\ Ra'anana, Israel
}

inabl@openu.ac.il ronen.gb@gmail.com

\begin{abstract}
Material published as part of this publication, either on-line or in print, is copyrighted by the Informing Science Institute. Permission to make digital or paper copy of part or all of these works for personal or classroom use is granted without fee provided that the copies are not made or distributed for profit or commercial advantage AND that copies 1) bear this notice in full and 2) give the full citation on the first page. It is permissible to abstract these works so long as credit is given. To copy in all other cases or to republish or to post on a server or to redistribute to lists requires specific permission and payment of a fee. Contact Publisher@InformingScience.org to request redistribution permission.
\end{abstract}

Transforming a school from traditional teaching and learning to a one-to-one (1:1) classroom, in which a teacher and students have personal digital devices, inevitably requires changes in the way the teacher addresses her role. This study examined the implications of integrating 1:1 computing on teachers' pedagogical perceptions and the classroom's educational discourse. A change in pedagogical perceptions during three years of teaching within this model was investigated. The research analyzed data from 14 teachers teaching in a junior high school in the north of Israel collected over the course of three years through interviews and lesson observations. The findings show that the 1:1 computing allows teachers to improve their teaching skills; however, it fails to change their fundamental attitudes in regard to teaching and learning processes. It was further found that the use of a laptop by each student does not significantly improve the classroom's learning discourse. The computer is perceived as an individual or group learning technology rather than as a tool for conducting learning discourse. An analysis of the data collected shows a great contribution to collaboration among teachers in preparing technology-enhanced lessons. The findings are discussed in terms of Bruner's (Olson \& Bruner, 1996) "folk psychology" and "folk pedagogy" of teachers and "the new learning ecology" framework in 1:1 classroom (Lee, Spires, Wiebe, Hollebrands, \& Young, 2015). One of the main recommendations of this research is to reflect on findings from the teaching staff and the school community emphasizing 1:1 technology as a tool for significant pedagogical change. It seems that the use of personal technology per se is not enough for pedagogical changes to take place; the change must begin with teachers'

perceptions and attitudes.

Keywords: one-to-one computing, 1:1, laptop integration in school, teachers' pedagogical perceptions, teacher "folk psychology" and "folk pedagogy", "the new learning ecology" framework, educational discourse in the classroom.

\section{Editor: Janice Whatley}

Submitted May 25, 2015; Revised September 11, 2015; Accepted: October 8, 2015 An earlier, shorter version of this paper was presented at the Chais conference 2015, in Raanana, Israel, and included in Y. Eshet-Alkalai, I. Blau, A. Caspi, N. Geri, Y. Kalman, \& V. Silber-Varod (Eds.), Proceedings of the 10th Chais Conference for the Study of Innovation and Learning Technologies 2015: Learning in the Technological Era. Raanana: The Open University of Israel. 


\section{Introduction}

Technology-enhanced learning environments are becoming more prevalent in the classroom, and digital tools have been used as intellectual partners for active participation in construction of knowledge (Jonassen, 2008; Salomon \& Perkins, 2005). Researchers, practitioners, and policymakers are engaged in debate about the effectiveness of learning and future promise of one-toone (1:1) computing in K-12 (Bebell, Clarkson, \& Burraston, 2014). The definition of one-to-one computing (Penuel, 2006), indicated 3 criteria: providing a laptop for every student in class, connecting the laptops to the internet, and focus on using laptops to complete academic tasks. With the emergence of new technological devices, the definition expanded to any portable device, such as smartphone, tablet, and netbook (Bebell et al., 2014; Lee, Spires, Wiebe, Hollebrands, \& Young, 2015; Shamir-Inbal \& Blau, 2014). The devices used in the 1:1 project explored in this study were laptops.

Some evidence suggests that 1:1 computing can impact students' achievement, discipline, attendance, and attitudes towards learning, as well as differentiate teaching and learning practices (Bebell et al., 2014; Harris \& Al-Bataineh, 2015; Rosen \& Beck-Hill, 2012). The qualitative analysis of K-12 students' reflections over time, presented in blog postings about the impact of 1:1 computing in their schools (Zheng, Arada, Niiya, \& Warschauer, 2014), revealed seven main themes: (1) more efficient and productive learning, (2) tools for better writing, (3) access to information, (4) engagement with new media, (5) remaining relevant in a technological world, (6) share and learn from peers, and (7) individualized and differentiated instruction.

However, as Cuban (2001) noted, from the pedagogical perspective, technology integration often mimics its analog counterpart rather than facilitates transformative change in teaching and learning. Despite a broadly accepted premise that 1:1 computing can change teaching methods, findings show only peripheral change in teachers' attitudes and educational practices (Bebell \& O'Dwyer, 2010; Penuel, 2006; Wilson, 2014). This study examined the implications of integrating a 1:1 computing with laptops in a large junior high school $\left(7^{\text {th }}-9^{\text {th }}\right.$ grades $)$ on teachers' pedagogical perceptions and the educational discourse in classroom.

\section{Types of Pedagogical Change and 1:1 Computing}

The pedagogical change in a technology-enhanced classroom may occur as a first order change or a second order change. A first order change is a behavioral change within the limits of the existing pedagogical principles, while in a second order change boundaries are breached, pedagogical principles change, and, as a result, behavior changes as well (Watzlawich, Weakland, \& Fisch, 1974). In a technology-enhanced classroom, a first order change can be manifested as the improvement of the prevalent teaching methods by using various demonstration tools and online information sources (Blau, 2011b). This use of technology does not change the pedagogical perceptions of the teacher, but rather serves her teaching method. The integration of technology in the processes of teaching and learning can also bring about a second order change, a paradigmatic change in the triad: teacher-student-content. Such a change is suggested by Scardamalia and Bereiter (1999) who seek to stop viewing the student as a consumer of content and the teacher as his supplier, but rather to see the two of them as partners in a learning community that is building new knowledge. According to this approach, the school needs to change from a supplier of services into a productive factory of knowledge construction, in which the input of students is acknowledged. As long as the integration of technology in the school is perceived as a technical issue, it will only achieve a first order pedagogical change. As soon as this integration is seen as an opportunity for changing pedagogical paradigm and the relationship between the teacher, students, and content, it can produce a second order change. This kind of change requires a change in the teacher's beliefs and in the entire school culture in which she operates (Ertmer \& Ottenbreit-Leftwich, 2010). 
First order change and second order change might reflect different models of teaching and learning. Bruner (Bruner, 1996; Olson \& Bruner, 1996) argued that educational decisions are deeply affected by our intuitive theories about how people learn (or "folk pedagogy") and our beliefs regarding how minds work and learning takes place (or "folk psychology"). As other adults, teachers have "folk psychology" - beliefs regarding the mind of their students and the process of learning - and these conceptions are reflected in the way teachers speak about their teaching and in their behavior in classroom (Olson \& Katz, 2011; Strauss, 2001). Bruner (Olson \& Bruner, 1996) suggest four models of perceiving teachers-learning processes: (1) learning as an acquisition of "know-how" (i.e., procedural knowledge) and students as "doers"; (2) learning as an acquisition of propositional knowledge and a transfer of content from teacher to student, and learners as "knowers"; (3) learning as a development of inter-subjective interchange that explores child's own perspective about the world, and children are independent "thinkers"; (4) learning as a management of "objective" knowledge and students as "knowledgeable" and able to connect their perspectives to existing cultural and scientific conventions.

All models suggested by Bruner can be found in 1:1 classrooms. For instance, technologyenhanced activities in which the teacher is the "model to imitate" or "source of knowledge" and the students are engaged in drill and practice or "consume" knowledge, lies on the first or second model of Bruner's that perceives the processes of teaching as "demonstration" or "knowledge transfer" and learning as "modeling" or "knowledge acquisition". As opposed to this, in technology-enhanced inquiry by students, on-topic discussions among peers, or collaborative learning, students function as "owners of knowledge" in terms of the third model of Bruner. With appropriate guidance and facilitation, the teacher can use technology for helping students ground their subjective knowledge in the accepted conventions of science and culture, and thus, move them to the fourth model of teaching and learning proposed by Bruner.

\section{The Role of Teacher and Educational Discourse in 1:1 Classroom}

The pedagogical promise that lies in the integration of 1:1 computing is realized only under optimal conditions (Ilomaki, 2008). These conditions include appropriate school leadership and the creation of teachers' professional communities of practice, the purpose of which is to build up knowledge and skills of teachers, coordinate their lesson plans, expose colleagues to appropriate educational apps, and collaborate on designing digital learning materials (Bebell et al., 2014; Downes, \& Bishop, 2015; Lindqvist, 2015). In order to feel a sense of ownership of the pedagogical change, a teacher must be an active partner in the formulation of the pedagogical vision of technology integration, and the processes of learning and professional development must focus on this change (Ertmer \& Ottenbreit-Leftwich, 2010). The assumption that only by using 1:1 laptops or other digital devices students will become more knowledgeable or more highly skilled is not valid from a pedagogical point of view (Fullan, 2011; Shamir-Inbal \& Blau, 2014). Personal technology may be an impetus for change on the condition that it is led by the pedagogy; thus, the teacher must be aware of her pedagogical attitudes and remain open to professional changes (Blau \& Peled, 2012).

The integration of 1:1 computing influences the teacher's role in the classroom (Bebell et al., 2014; Bebell \& Kay, 2010; Blau, Peled, \& Nusan, 2014; Fleischer, 2012). Fleischer (2012) found that $1: 1$ technology enables teachers to work with more flexibility relative to the existing curricula. Teachers reported that the 1:1 computing enabled them to teach more, in more depth, and in a shorter period of time (Silvernail, Pinkham, Wintle, Walker, \& Bartlett, 2011). The objectives of 1:1 initiatives underlie hidden or explicit expectation of changing the teaching methods (Rosen \& Beck-Hill, 2012). For the most part, the attitude towards this change is described as the adoption of more student-centered teaching practices that promote higher-order thinking skills, " $21^{\text {st }}$ century skills" and "future competences" of students (Bebell et al., 2014; Shamir-Inbal \& Blau, 2014). 
On the other hand, these practices challenge teachers in terms of 1:1 classroom management (Blau et al., 2014; Tallvid, Lundin, Svensson, \& Lindström, 2015). Some authors (Lee et al., 2015) even link 1:1 computing to "the new learning ecology", in which (1) technology enables immediate and constant access to information; (2) the teacher acts as content expert, facilitator, consultant, mentor, and improvisationist; (3) students are more self-directed, self-regulated, curious, and creative learners; and (4) the learning process is intense, personalized, and relevant to students.

One of the ways in which pedagogical change is manifested is educational discourse the teacher carries on in the classroom (Cazden, 1998). The prevalent pattern of educational discourse in classroom was first identified by Sinclair and Coulthard (1975) as IRF and later by Mehan (1979) as IRE sequences. The sequence is initiated by the teacher (represented by "I") asking a question mostly relating to already known information. Then the pupils are supposed to respond (represented by "R"), and the short sequence is closed by the teacher's feedback (represented by "F") or evaluation (represented by "E"). According to Cazden (1998), these patterns govern educational discourse in a teacher-centered classroom. She claimed that teachers do not use it for the sake of exploring ideas or building new knowledge, but mainly to maintain control. Recent findings in the 1:1 learning environment support this claim (Blau et al., 2014; Wilson, 2014). Wertsch (1998) recognized that this pattern of educational discourse is the most resistant to change across classrooms.

The IRE is still the most widespread discourse structure to be found in classrooms all over the world (Rogers, 2011), including 1:1 classrooms (Wilson, 2014). However, one should consider this triadic structure of educational discourse as a basis for different pedagogical goals (Molinari, Mameli \& Gnisci, 2013). For example, 1:1 computing can facilitate online educational interaction of students with teachers and with more advanced peers, as a part of both in- and out-of-class learning activities (Shamir-Inbal \& Blau, 2014). In terms of Social Constructivism (Vygotsky, 1978), we can assume that such interactions and educational discourse of students with the teacher and more advanced peers in 1:1 settings provides online scaffolding. Thus, through educational discourse, 1:1 classroom can advance students within their Zone of Proximal Development (ZPD) - beyond their current level or understanding and competence.

In sum, the literature reviewed above focuses on pedagogy, the role of teachers, and the educational discourse in 1:1 classrooms. The conceptual frameworks we used to discuss these issues are first and second order change, Bruner's models of teaching and learning, and "the new learning ecology". Previous studies showed that 1:1 technology can be a powerful pedagogical tool, but in many cases this model preserves teacher-centered instructional practices. Consequently, the educational potential of 1:1 computing remains only partially realized and does not produce deep pedagogical changes.

\section{The Study's Objective}

This study examined the implications of 1:1 computing on the pedagogical perspectives of teachers and educational discourse in classroom. This study was carried out with a qualitative research approach. The conceptual framework for analyzing pedagogical perspectives of teachers used in this study is the "four models" of Bruner (Olson \& Bruner, 1996) reflecting the "folk psychology" and "folk pedagogy" of teachers, and "the new learning ecology" framework in 1:1 classroom (Lee et al., 2015). Educational discourse in 1:1 classroom will be addressed in terms of the IRE pattern and socio-constructivist claim of promoting students within their ZPD through interactions of students with the teacher and more advanced peers.

The following research questions attempted to expose the teachers' perspectives and their expression in teaching: 
1. Whether and how teachers' pedagogical perspectives have changed during the three years of teaching in the program?

2. Whether and how 1:1 computing affected the educational discourse in the class?

3. Whether and how 1:1 computing affected collaboration among the teachers in the design of technology-enhanced lessons?

\section{The Method}

\section{Participants}

The participants in the study were eleven female teachers and three male teachers from a variety of disciplines, in a large regional junior high school $\left(7^{\text {th }}-9^{\text {th }}\right.$ grades $)$ in the north of Israel, which had integrated 1:1 laptop initiative for teachers and students (the KATOM initiative - the acronym of "Classroom, Student, and Teacher" in Hebrew). All the teachers who taught in 1:1 classrooms for three years $(2011,2012,2013)$ took part in the study. These teachers volunteered to teach in 1:1 classroom during the first wave of the integration. The age of the participants was normally distributed, the average was 44.1 years. The teachers were from the following disciplines: two teachers of math, science, Hebrew (native language), literature, English (SL), Bible studies, and one history teacher.

All teachers participated in the program received a standard initial training provided by the Israeli Ministry of Education (30 hours). The initial training focused on basic digital competences and the ways of incorporating technology in teaching in order to enhance learning. In addition, ongoing professional development was provided by the 1:1 laptop initiative and included weekly meetings of the participants with the instructor holding the M.A. degree in Educational Technology and Learning Systems. The ongoing professional development was based on three parallel segments derived from the Technological pedagogical and content knowledge (TPACK) model (Mishra \& Koehler, 2006): (1) technological knowledge and proficiency (TK), which had the objective to create a first order change; this segment was based on weekly group work and personal support according to each teacher's needs; (2) subject related team work; for instance, the science teachers met weekly in order to connect their unique content knowledge to their technological knowledge (TCK); and (3) teaching with technology - experimenting and evaluating in their classes ways to enhance their teaching and student's learning with technology. This model (TPACK) leads to a second order change. A follow up in the subject-related teams and with the program's instructor enabled peer support and spread of pedagogical ideas and best practices.

\section{Research Tools and Procedure}

At the end of the first semester and the second semester of each school year, non-participant observations were carried out in double lessons of each teacher who taught in 1:1 classroom. The observation protocol included a description of the classroom, descriptions of events, and related commentary (for details see Lee et al., 2015). Immediately after the observation, a semistructured interview was conducted with the teacher (see Appendix). The proximity of the interview to the observation allowed immediate reference to the lesson, in which personal laptops were used. A total of six hour-and-a-half observations and six hour-long interviews were carried out with each of the 14 teachers. The observations' notes were typed. The interviews were audio recorded and transcribed.

At the end of the third year of the initiative, a final meeting was conducted, at which each of the curricular teams reported on and demonstrated examples of the way in which they integrated 1:1 computing in teaching and learning. In addition to the curriculum team coordinator's report, each 
of the teachers on the team expressed his or her reflections on teaching in 1:1 classroom. This meeting also was audio recorded and transcribed.

Our data analysis consisted of scrutinizing our open-ended observations and resulting field notes as well as the data from the follow-up interview sessions. The analysis of the final meeting notes was also conducted as part of confirming and disconfirming emerging findings. We applied the method of thematic analysis by the classifications of generating initial codes, defining and naming themes, reviewing themes, and searching for themes (Vaismoradi, Turunen, \& Bondas, 2013). It has been suggested that thematic analysis, as a flexible and useful research tool, provides a rich and detailed, yet complex, account of the data (Braun \& Clarke, 2006).

\section{Results and Discussion}

\section{1:1 Computing and Teachers' Pedagogical Perceptions}

Already in the first year of implementation of the program, all the teachers recognized the possibility of 1:1 computing to change teaching practices. One of the teachers emphasized that the opportunity allowed her "to step away from the teacher-centered approach to a situation in which students are provided with a variety of opportunities. For example, during the today's lesson my students conducted independent research, watched educational video, used simulation, and discuss their understanding with peers" [T2]. This finding is consistent with Lee et al.'s (2015) study that links 1:1 computing to "the new learning ecology". The activities in the citation reflect three out of four elements of the new learning ecology framework: 1:1 computing enables immediate access to information; teacher acts as content expert, facilitator, and mentor; and the learning process is more intense, personalized, and relevant to students.

However, only a minority (three out of fourteen teachers) saw 1:1 computing as an opportunity for substantial pedagogical change. It appears, therefore, that only a fifth of the teachers in the initiative arrived at what could be interpreted as second order change (Watzlawick et al., 1974). In contrast, most of the teachers were satisfied with first order change. They identified the main objective of teaching in 1:1 classroom as reinforcement of existing teaching methods, diversification of demonstration tools, and exposure of students to various information sources. For instance, some of the teachers used laptops mostly for taking notes: "The laptop replaces the traditional notepad - it can help students organizing learning materials and revising them before an exam. But it can't replace frontal instruction, the conveying of information by the teacher." [T6].

Furthermore, most of the teachers perceived frontal instruction as their main teaching method, and some explained that this teaching style arises from their need to control the class. This finding is consistent with the need for control documented in a previous study of 1:1 computing (Wilson, 2014). Moreover, some teachers noted that traditional instruction without technology allows them to carry on more meaningful discussions in the classroom and were dissatisfied with 1:1 computing, which did not allow them to hear their students' opinions and monitor students' progress. This argument was also presented by the participants of Wilson's study and can be attributed to the need to control students.

Comparative analysis between the observations and the interviews shows discrepancies between the pedagogical principles that our participants declared in the interviews and the teaching practices observed in their lessons. It was apparent from the interviews that most of the teachers recognize the potential of 1:1 computing for implementing the principles of constructivist learning. However, consistent with previous results (Blau et al., 2014), the teachers in our study were aware of these principles on a declarative level: this awareness was not manifested in their teaching. From the observations it was found that (1) in most of the lessons the laptops were used for the entire class demonstrations and for independent work by students, (2) few teachers initiated a 
process of collaborative learning in small groups, (3) most of the learning tasks had one correct answer that the students were meant to arrive at. In terms of Bruner's "folk pedagogy" (Bruner, 1996; Olson \& Bruner, 1996), the finding suggests that these participants assume that teaching is a process of knowledge transmission, according to which the teacher is the "owner of knowledge" and his role is to transfer a defined "body of knowledge" to the students. This finding reinforces the previous conclusions that the use of computers improves existing teacher-centered instruction, but does not bring about essential pedagogical changes (Cuban, Kirkpatrick, \& Peck, 2001; Ilomaki, 2008; Magen-Nagar, Rotem, Inbal Shamir, \& Dayan, 2014; Wilson, 2014). Nevertheless, our findings differ from the argument of Bruner (Olson \& Bruner, 1996), according to which beliefs about the nature of learning - "folk psychology" - are consistent with teaching methods "folk pedagogy". We can explain this contradiction by the different population of our study - inservice teachers that receive ongoing pedagogical-technological professional development. It seems that professional development changes only "folk psychology", at least on its declarative level, but "folk pedagogy" in 1:1 classroom remains unchanged. This explanation is consistent with previous differentiation between teachers' folk psychology and pedagogy and their professional knowledge (Strauss, 2001). Future studies can explore this apparent gap between folk psychology and folk pedagogy of teachers on one hand, and professional knowledge of in-service teachers in the context of technological-pedagogical professional development on the other hand.

Only three out of fourteen teachers explicitly described the ways in which 1:1 computing enables them to put the constructivist approach into practice in the classroom and perceive themselves as facilitators of learning processes and mentors of their students. For example, one of these teachers emphasized the responsibility of teachers to differentiate the learning process in 1:1 classroom [T3]: "Learning with laptops allows differentiation. It's possible to reach every student, and I think it is important to adapt the learning process in a heterogenic classroom to different academic levels of my students". Another teacher argued that in 1:1 classroom teacher should pass to students more responsibility for the learning process and develop their self-regulation competences: "The students assume responsibility for their own learning because in 1:1 classroom it depends on them whether they learn or not. If I let my students learn how to be independent, I think that they gain additional important skills. They know how to learn, to solve complex problems, to overcome challenges" [T2]. These findings are consistent with the Lee et al.'s (2015) claim, according to which 1:1 computing promotes "the new learning ecology". These citations revealed the following three elements of the new learning ecology framework: teacher in 1:1 classroom acts as facilitator, consultant, and mentor; students are more self-directed and self-regulated learners; and the learning process is more personalized and relevant to students.

These three teachers expressed dissatisfaction with the prevalent pedagogical perceptions and did not find first order change to be sufficient in 1:1 classroom. In terms of Bruner's teachinglearning models (Bruner, 1996; Olson \& Bruner, 1996), we can argue that these teachers view their students, according to the second and the third model, as independent "thinkers" and "knowledgeable". These teachers acknowledge the fact that knowledge is constantly developing, is found in everyone, and is therefore constructed and cannot be transferred, but rather grounded in the conventions of science and culture. Thus, the role of teacher in 1:1 classroom is not only to facilitate the construction of knowledge by students, but also to provide (digital and analog) scaffolds that will frame the ideas and intuitive understanding of their students in the existing scientific and cultural heritage (Barzilai \& Blau, 2014). In other words, the role of teacher goes beyond the constructivism according to the third model of Bruner, towards the fourth model of teaching and learning, which deals with facilitating the construction of "objective knowledge" by students. 


\section{The Evolvement of Pedagogy over Time}

Over time, digital competences of the teachers and their abilities to design technology-enhanced lessons have improved. This improvement was apparent in both the time needed to design these lessons and the quality of the lessons. A science teacher, who estimated during the first year that she spent more time in preparations, stated at the end of the third year that "As time goes by, it becomes easier. At the start of the 1:1 initiative it would take about two hours and in most cases it wasn't as well planned as today's lesson. Now, if I know what I want to design and I am focused, the preparation takes from 30 minutes to an hour" [T8]. The shortening of the lesson design time after three years of 1:1 initiative is highly significant, since previous studies that did not examine changes over time, presented the time required for digital design as a hindering factor in the integration of 1:1 computing (Carenzio, Triacca, \& Rivoltella, 2014; Cuban et al., 2001; Guitert \& Vazquez, 2013).

However, three years of teaching in 1:1 classroom did not change the pedagogical perspectives of the teachers and the way in which they use laptops in the classroom. This is an example of using the laptops at the end of the third year: "The teachers and students write answers together. One of the students composes the answer and the teacher suggests what they should add in order to get an acceptable answer. The individual laptops of students are basically used as a whiteboard-for working with the whole class on editing "right answers"." [L83].

Moreover, after three years of 1:1 initiative in the school, it did not bring additional teachers to make a second order pedagogical change (Watzlawick et al., 1974). In terms of Bruner's models (Bruner, 1996; Olson \& Bruner, 1996), time did not bring about a shift from the teaching-learning process as "transfer of knowledge" from teacher to student, according to the second model, to the process of learning as active construction of knowledge by the students, as described by the third and fourth models. Those three teachers who defined themselves in the first year as "facilitators" of learning processes conserved this definition at the end of the third year as well, but surprisingly, not even one additional teacher joined them. Over time, the observations consistently showed that these three teachers expanded their repertoire of 1:1 computing in the way consistent with the principles of constructivist pedagogy -they used technology to enable inquiry learning of students, problem solving, and collaborative learning. The only exception was presented in the interview by one of these three teachers and it described the change over time from teacher-centered to student-centered teaching: "Before the initiative, a large proportion of the time in classroom was spent on solving discipline problems and then, on frontal instruction, in which I was the source of knowledge. For example, I read them the poem, explained the words, analyzed it for them, and gave them some questions as homework. Today, as you could see, there's no need for that. Now they listen to the poem on the computer, they read it by themselves, they find the words that they don't understand in the online dictionary and read the poem 's interpretation on the web. After analyzing it according to characteristics summarized on the class website, each student has his or her final product and we begin a discussion. Thus, their learning with laptops is selfdirected and my role is mainly to monitor this process and facilitate the discussion at the end of the process, in order to insure that there are no misinterpretations" [T10]. In terms of Lee et al. (2015), the activity in the citation presents all four components of "the new learning ecology" in 1:1 computing: technology enables immediate access to information; teacher acts as content expert, facilitator, and consultant; students are self-directed; and the learning process is personalized and relevant to students.

Similarly, the teachers' perceptions regarding the amount of content covered in 1:1 classroom did not change over the years either. The teachers, who claimed in the first year of the initiative that the amount of content covered was unimportant or that they sufficiently covered the material, repeated the claim in the third year as well. On the other hand, teachers, who in the first year complained of delays caused by the 1:1 computing, repeated the same complain after three years of 
the initiative. These findings are similar to the results of 1:1 initiative in Spain (Guitert \& Vazquez, 2013). The participants' claims about the sense of advancing in the content provide additional testimony for the prevalence of Bruner's second model (Bruner, 1996; Olson \& Bruner, 1996) in "folk psychology" of teachers. Consistent with the claim of Strauss (2001), interviews with the majority of our participants showed that subject-matter content is perceived as a body of information of a certain scope, which exists beyond the consciousness of the students, is transferred by the teacher during the lesson, and is acquired by the students. Unfortunately, our findings suggest that over time 1:1 computing does not change, but on the contrary, reinforces beliefs of teachers about the nature of learning. The absence of change over time in the pedagogical perceptions of the teachers who participated in the present study suggests that "folk psychology" of teachers is quite fixed and does not change substantially as a result of changes in the learning environment. Future research should examine this explanation with a larger and more diverse sampling of teachers.

Our findings in regard to the changes over time in 1:1 classroom support the claim that technological innovations do not guarantee changes in pedagogical perceptions of teachers (Cuban, 2001). Changing pedagogical perceptions requires professional development of teachers as a community of practice and explicit encouragement of the school leadership (Blau \& Presser, 2013). Neither professional development of the teachers nor the school leadership and stakeholders from the 1:1 initiative had aims of changing pedagogical beliefs of the teachers, which, according to Ertmer and Ottenbreit-Leftwich (2010), is a necessary precondition for bringing about second order change.

\section{Characteristics of the Educational Discourse}

Regarding the educational discourse, our data showed the same differences between the three constructivist-minded teachers and the rest of the participants. Most of the lessons of the three teachers included a substantial element of independent or group learning, and both observations and interviews revealed that complex discourse occurred during the lessons between the students and the teacher and between peers. One of the teachers stated, "... I believe that class should include basic data acquisition, group discussion, work in pairs and larger groups, a lot of research and discovery, as well as the traditional assignments and tests... I think that the laptops have changed the balance between the various teaching methods..... In 1:1 classroom there are much more discussions related to student learning outcomes, much more interactions, and on-demand scaffolding of student understanding. " [T3].

In the lessons of the majority of teachers, however, it appears that the use of laptops mostly encouraged independent learning of students and left less opportunity for educational discourse in the classroom. Moreover, among all the participants, 1:1 computing was not used at all for creating online educational discourse. It appears that 1:1 computing does not substantially change the patterns of communication between the teacher and the students, and among peers in the classroom. Our data is consistent with the recent data regarding communication in 1:1 classroom presented by Swallow (2015). It seems that the characteristics of the educational discourse are determined by the pedagogical perceptions and not by the technological tools available to teachers. In opinion of most of the teachers who took part in the study, the meaningful educational discourse occurs during face-to-face group discussion, and not online. The laptop is perceived as a tool for enhancing independent or group learning, but not as a tool associated with the educational discourse, neither in the class nor out-of-class. Thus, in terms of Social Constructivism (Vygotsky, 1978), one of the potential benefits of 1:1 computing for advancing the students within the Zone of Proximal Development through online learning-related interactions with the teacher and/or more advanced peers has remained unrealized. Surprisingly, this potential for scaffolding students' understanding by online discussions is not a part of "the new learning ecology" frame- 
work for 1:1 computing (Lee et al., 2015). We recommend exploring this issue in future studies in both, in-class and out-of-class online discussions, and including online interactions in the new learning ecology framework.

\section{Collaboration among Teachers on Digital Learning Design}

From the reports of the curricular teams has arisen the major importance of the collaboration on designing digital learning materials. Collaboration within a team can both improve the quality of the outcome (Blau \& Caspi, 2009; Caspi \& Blau, 2011) and save the time invested on preparing 1:1 lessons. As stated by a teacher from the science department, "We work as a team, so we distribute the work load. We work together for approximately 30 minutes per day" [T8].

Collaboration among teachers is a significant factor in improving the level of teaching and an integral part of teacher's professional development (Daly, Moolenaar, Bolivar, \& Burke, 2010; Downes, \& Bishop, 2015). Indeed, it appears that the teachers' ability to learn and collaboratively design digital learning materials adapted to specific needs of their students, is one of the most important conditions for the success of the 1:1 initiative (Lindqvist, 2015). That being said, it's clear that the level of functioning of the curricular team depends on the human factor, regardless of the requirements of the initiative leadership and educational decision-makers (Blau \& Hameiri, 2012). The initiative created the necessity for adapting curriculum and to devote more time to collaborative design of digital learning materials (Downes, \& Bishop, 2015). All the teachers referred to this necessity in positive terms. It appears that peer learning among teachers and exposure to appropriate sources of information, various models of technology-enhanced lessons, and different apps, can significantly contribute to the design of 1:1 lessons (Lindqvist, 2015). Moreover, the adoption of collaborative teamwork by teachers in the professional context could spread into the classrooms and encourage the teachers to promote collaborative learning among their students (Blau, 2011a). In future research, we recommend to explore the relationship between the professional collaboration among teachers and the collaborative learning of their students.

\section{Conclusion and Implications}

This study analyzed pedagogy, the role of teachers, and educational discourse in 1:1 classrooms in terms of first and second order change, Bruner's models of teaching and learning, and "the new learning ecology" framework. The study reinforces the claim that technology is a powerful educational tool, but technology per se does not produce deep pedagogical changes. One-to-one computing expands the educational repertoire, but preserves both student-centered and teachercentered instructional practices. Moreover, the findings indicate a gap between the teachers' declared insights about optimal technology-enhanced learning and the translation of those insights into actual teaching practices.

The study has implications for the integration of 1:1 computing for enhancement of teaching and learning processes. The decision makers in education systems and schools that aspire to promote pedagogical changes need to clarify the pedagogical principles, or "folk pedagogy", of the teachers in the context of technology integration and teacher professional development. Based on the findings, we can recommend the encouragement of online discourse among students, both inclass and out-of-class, as a mean for the advancement of learning processes. In addition, we recommend educational decision-makers and designers of teacher professional development programs to emphasize the processes of collaboration among teachers in the design of technologyenhanced lessons. These processes require ongoing encouragement of educational leadership and appropriate teacher training. 


\section{Acknowledgement}

This research was financed by the chief scientist of the Israeli Ministry of Education

\section{References}

Barzilai, S., \& Blau, I. (2014). Scaffolding game-based learning: Impact of learning achievements, perceived learning, and game experiences. Computers \& Education, 70, 65-79.

Bebell, D., Clarkson, A., \& Burraston, J. (2014). Cloud computing: Short term impacts of 1: 1 computing in the sixth grade. Journal of Information Technology Education: Innovations in Practice, 13, 129151. Retrieved from http://www.jite.org/documents/Vol13/JITEv13IIPp129-152Bebell0739.pdf

Bebell, D., \& Kay, R. (2010). One to one computing: A summary of the quantitative results from the Berkshire wireless learning initiative. The Journal of Technology, Learning and Assessment, 9(2). Retrieved September 3, 2015 from http://ejournals.bc.edu/ojs/index.php/jtla/article/viewFile/1607/1462$\underline{\text { accessdate }=19}$

Bebell, D., \& O’Dwyer, L. M. (2010). Educational outcomes and research from 1:1 computing settings. Journal of Technology, Learning, and Assessment, 9(1). Retrieved September 3, 2015 from http://files.eric.ed.gov/fulltext/EJ873675.pdf

Blau, I. (2011a). E-collaboration within, between, and without institutions: Towards better functioning of online groups through networks. International Journal of e-Collaboration, 7, 22-36.

Blau, I. (2011b). Teachers for "Smart classrooms": The extent of implementing of an Interactive Whiteboard-based professional development program on elementary teachers' instructional practices. Interdisciplinary Journal of E-Learning and Learning Objects - IJELLO, 7, 275-289. Retrieved from http://www.ijello.org/Volume7/IJELLOv7p275-289Blau758.pdf

Blau, I., \& Caspi, A. (2009). What type of collaboration helps? Psychological ownership, perceived learning, and outcome quality of collaboration using Google Docs. In Y. Eshet-Alkalai, A. Caspi, S. Eden, N. Geri, \& Y. Yair (Eds.), Learning in the technological era (pp.48-55). Ra'anana, Israel: The Open University of Israel.

Blau, I., \& Hameiri, M. (2012). Teachers-families online interactions and gender differences in parental involvement through school data system: Do mothers want to know more than fathers about their children? Computers \& Education, 59, 701-709.

Blau, I., \& Peled, Y. (2012). Teachers' openness to change and attitudes towards ICT: Comparison of laptop per teacher and laptop per student programs. Interdisciplinary Journal of E-Learning and Learning Objects, 8, 73-82. Retrieved from http://www.ijello.org/Volume8/IJELLOv8p073-082Blau0800.pdf

Blau, I., Peled, Y., \& Nusan, A. (2014). Technological pedagogical and content knowledge (TPACK) in one-to-one classroom: Teachers developing "Digital Wisdom". Interactive Learning Environments. DOI: $10.1080 / 10494820.2014 .978792$

Blau, I., \& Presser, O. (2013). e-Leadership of school principals: Increasing school effectiveness by a school data management system. British Journal of Educational Technology, 44(6), 1000-1011.

Braun, V., \& Clarke, V. (2006). Using thematic analysis in psychology. Qualitative Research in Psychology, 3(2), 77-101.

Bruner, J. S. (1996). The culture of education. Harvard University Press.

Caspi, A., \& Blau, I. (2011). Collaboration and psychological ownership: How does the tension between the two influence perceived learning? Social Psychology of Education: An International Journal, 14, 283-298.

Carenzio, A., Triacca, S., \& Rivoltella, P. C. (2014). Education technologies and teacher's professional development. The project Motus (Monitoring Tablet Utilization in School) run by Cremit. Remresearch on Education and Media, 6(1), 25-38. 
Cazden, C. (1998). Classroom discourse: The language of teaching and learning. Portsmouth, NH: Heinemann.

Cuban, L. (2001). Oversold and underused: Reforming schools through technology, 1980-2000. Cambridge, MA: Harvard University Press.

Cuban, L., Kirkpatrick, H., \& Peck, C. (2001). High access and low use of technologies in high school classrooms: Explaining an apparent paradox. American Educational Research Journal, 38(4), 813-834.

Daly, A. J., Moolenaar, N. M., Bolivar, J. M., \& Burke, P. (2010). Relationships in reform: The role of teachers' social networks. Journal of Educational Administration, 48(3), 359-391.

Downes, J. M., \& Bishop, P. A. (2015). The intersection between 1: 1 laptop implementation and the characteristics of effective middle level schools. RMLE Online, 38(7), 1-16. Retrieved September 3, 2015 from https://www.amle.org/portals/0/pdf/rmle/rmle vol38 no7.pdf

Ertmer, P. A., \& Ottenbreit-Leftwich, A. T. (2010). Teacher technology change: How knowledge, confidence, beliefs, and culture intersect. Journal of Research on Technology in Education, 42(3), 255-284.

Fleischer, H. (2012). What is our current understanding of one-to-one computer projects: A systematic narrative research review. Educational Research Review, 7(2), 107-122.

Fullan, M. (2011). Choosing the wrong drivers for whole system reform. Melbourne, Australia: Centre for Strategic Education.

Guitert, M., \& Vázquez, A. (2013). Teacher perceptions of the time factor in One Laptop per Child. eLearn Center Research Paper Series, (7), 06-14.

Harris, J., \& Al-Bataineh, A. (2015). One to one technology and its effect on student academic achievement and motivation. In Proceedings of Global Learn 2015 (pp. 579-584).

Ilomäki, L. (2008). The effects of ICT on school: teachers' and students' perspectives. Annales Universitatis Turkuensis B 314.

Jonassen, D. (2008). Meaningful learning with technology. Upper Saddle River, NJ: Pearson Merrill Prentice Hall.

Lee, J., Spires, H., Wiebe, E., Hollebrands, K., \& Young, C. (2015). Portraits of one-to-one learning environments in a new learning ecology. International Journal of Learning, Teaching and Educational Research, 10(3), 78-101.

Lindqvist, M. J. H. (2015). Gaining and sustaining TEL in a 1: 1 laptop initiative: Possibilities and challenges for teachers and students. Computers in the Schools, 32(1), 35-62.

Magen-Nagar, N., Rotem, A., Inbal-Shamir, T., \& Dayan, R. (2014). The effect of the national ICT plan on the changing classroom performance of teachers. In Eshet-Alkalai,Y., Blau, I., Caspi, A., Gary, N., Kalman, Y., \& Zilber-Varod, V., \& Yair, Y.(Eds.), Learning in the Technological Era (p.104-111). Ra'anana, Israel: The Open University of Israel.

Mehan, H. (1979). Learning lessons: Social organization in the classroom. Cambridge, MA: Harvard University Press.

Mishra, P., \& Koehler, M. (2006). Technological pedagogical content knowledge: A framework for teacher knowledge. Teachers College Record, 108(6), 1017-1054.

Molinari, L., Mameli, C., \& Gnisci, A. (2013). A sequential analysis of classroom discourse in Italian primary schools: The many faces of the IRF pattern. British Journal of Educational Psychology, 83(3), 414-430.

Olson, D. R., \& Bruner, J. S. (1996). Folk psychology and folk pedagogy. In D. R. Olson \& N. Torrance (Eds.), Handbook of education and human development: New models of learning, teaching, and schooling (pp. 9-27). Cambridge, MA: Blackwell. 
Olson, D. R., \& Katz, S. (2001). The fourth folk pedagogy. In B. Torff \& R. J. Sternberg (Eds.), Understanding and teaching the intuitive mind (pp. 243-263). Mahwah, NJ: Lawrence Erlbaum.

Penuel, W. R. (2006). Implementation and effects of one-to-one computing initiatives: A research synthesis. Journal of Research on Technology in Education, 38(3), 329-348.

Rogers, R. (Ed.). (2011). An introduction to critical discourse analysis in education. Routledge.

Rosen, Y., \& Beck-Hill, D. (2012). Intertwining digital content and a one-to-one laptop environment in teaching and learning: Lessons from the time to know program. Journal of Research on Technology in Education, 44(3), 225-241.

Salomon, G., \& Perkins, D. N. (2005). Do technologies make us smarter? Intellectual amplification with, of, and through technology. In D. D. Preiss \& R. Sternberg (Eds.), Intelligence and technology (pp. 71-86). Mahwah, NJ: LEA.

Scardamalia, M., \& Bereiter, C. (1999). Schools as knowledge building organizations. In D. Keating \& C. Hertzman (Eds.), Today's children, tomorrow's society: The developmental health and wealth of nations (pp. 274-289). New York: Guilford.

Shamir-Inbal, T. \& Blau, I. (2014). How the implementation of tablet computers impacts learning and pedagogy and promotes "digital wisdom" of students and teachers in the elementary school? Paper presented at the 8th International Technology, Education and Development Conference - INTED2014. Valencia, Spain.

Silvernail, D. L., Pinkham, C., Wintle, S. E., Walker, L. C., \& Bartlett, C. L. (2011). A middle school oneto-one laptop program: The Maine experience. Gorham, ME: Maine Educational Policy Research Institute, University of Southern Maine.

Sinclair, J. \& Coulthard, R.M. (1975). Toward an analysis of discourse. Oxford: Oxford University Press.

Strauss, S. (2001). Folk psychology, folk pedagogy and their relations to subject matter knowledge. In B. Torff \& R. J. Sternberg (Eds.), Understanding and teaching the intuitive mind (pp. 217-242). Mahwah, NJ: Lawrence Erlbaum.

Swallow, M. (2015). The year-two decline: Exploring the incremental experiences of a 1:1 technology initiative. Journal of Research on Technology in Education, 47(2), 122-137.

Tallvid, M., Lundin, J., Svensson, L., \& Lindström, B. (2015). Exploring the relationship between sanctioned and unsanctioned laptop use in a 1: 1 classroom. Journal of Educational Technology \& Society, 18(1), 237-249.

Vaismoradi, M., Turunen, H., \& Bondas, T. (2013). Content analysis and thematic analysis: Implications for conducting a qualitative descriptive study. Nursing \& Health Sciences, 15(3), 398-405.

Vygotsky, L. S. (1978). Mind and society: The development of higher mental processes. Cambridge, MA: Harvard University Press.

Watzlawick, P., Weakland, J. H., \& Fisch, R. (1974). Change: Principles of problem formation and problem resolution. WW Norton.

Wertsch, J. (1998). Mind as action. New York: Oxford University Press.

Wilson, N. (2014). Interrogating the divide: A case study of student technology use in a one-to-one laptop school. Doctoral Dissertation. University of Massachusetts - Amherst. Paper 266. Retrieved September 3, 2015 from http://scholarworks.umass.edu/cgi/viewcontent.cgi?article=1172\&context=dissertations 2

Zheng, B., Arada, K., Niiya, M., \& Warschauer, M. (2014). One-to-one laptops in K-12 classrooms: voices of students. Pedagogies: An International Journal, 9(4), 279-299. 


\section{Appendix: Guiding questions for semi-structured interviews with teachers}

1. In your opinion, what are the goals of one-to-one computing project on a school level?

2. What are your personal goals as a teacher in one-to-one computing classroom? Why did you decide to join the group of teachers that has volunteered to teach in one-to-one classes? What were your expectations and concerns before launching the program? Whether and how is the reality different from the expectations?

3. Describe the ways you use a laptop: 1-in everyday life; 2 -for pedagogical purposes. On average, how much time do you invest into preparing technology-enhanced lesson?

4. Do you succeed in "transferring the content" you planned for the lesson in one-to-one classroom? How, if at all, your role as a teacher in one-to-one class is different from your role as a teacher in regular class?

5. Describe how, in your opinion, students should learn with laptops in one-to-one classroom. What is important to pay attention to? Please provide an example, when and what type of activity is not suitable for using the technology.

6. Some teachers argue that students "waste" too much time searching for information online. What do you think about this statement? Can you provide an example of a task that requires students to work with online information sources?

7. To what extent is the lesson I have just observed typical for "regular" one-to-one computing lesson in your class? To what extent is the atmosphere in the lesson observed typical for one-to-one classroom?

8. What was your goal in the lesson I have observed? What is your impression of the learning process that took place during the lesson? Can you provide an example of "typical" learning activity that involves technology?

9. Do you see the change in a way students learn compared to the regular class? What about the change in the classroom atmosphere? Do students enjoy technologyenhanced lessons? How about the change in interaction between students inside and outside the classroom?

10. To what extent, if at all, one-to-one classroom management is different from traditional classroom management? How, if at all, are you aware of sites that students visit during the lesson? (Perhaps during the lesson kind-hearted boys are looking for girls who have no money to buy clothes...).

11. Do you allow students to use online communication during the lesson? Explain why.

12. Are technology-enhanced lessons available for students and visible for parents and the school staff through the classroom website? Can you show an example? 


\section{Biographies}

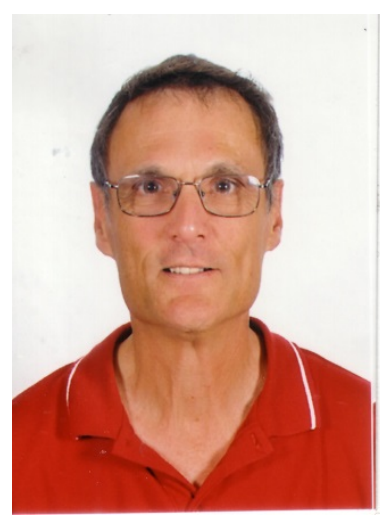

Yehuda Peled is a Senior Lecturer and the head of the information studies department at the Western Galilee College - Israel. He holds a PH.d in Educational Technology from the Technion-Israel Institute of Technology - Haifa.

His research interests include the use of collaborative environments in teaching and learning, various aspects of online and F2F academic dishonesty, Cyberbullying as well as organizational aspects of technology adoption in education.

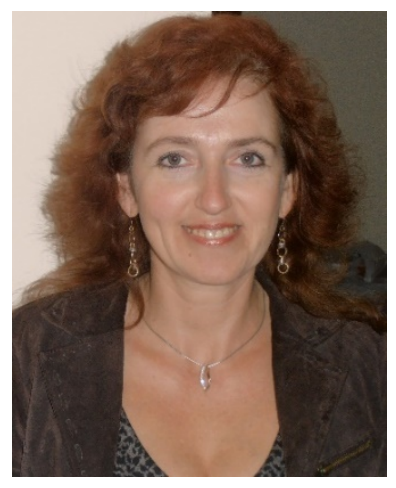

Ina Blau is a Senior Lecturer in the Department of Education and Psychology at the Open University of Israel. She holds a Ph.D. in ELearning and Cyber-Psychology from the University of Haifa, Israel. Her research interests include social aspects of e-communication and eleadership, integration of innovative technologies in K-12, academia and organizations, mobile learning and interaction, digital literacy skills, online privacy in social networking, and psychological ownership in e-collaboration.

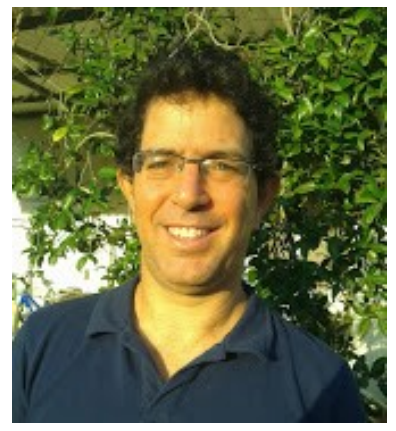

Ronen Grinberg is a graduate student of the Open University of Israel and Alma's educational center in Tel Aviv. Ronen works as a pedagogical advisor in the Branco Weiss Institute, expert in thinking development and teaching for understanding methods. The study presented in this paper is part of his learning toward a Master's Degree at the Open University of Israel, majoring in learning technologies, under the supervision of Dr. Ina Blau. 